\title{
A novel evaluation technique for measuring the distance between the anastomosis and intersphincteric groove via three- dimensional endoanal ultrasonography in children with Hirschsprung disease
}

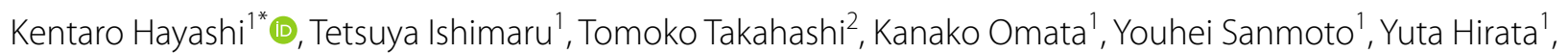
Hiroshi Kawashima ${ }^{1}$ and Tadashi Iwanaka ${ }^{3}$

\begin{abstract}
Background: This study aimed to describe our experience with three-dimensional endoanal ultrasonography (3D-EAUS) in patients who underwent surgery for Hirschsprung disease and to summarize the relationship between postoperative anal function and the distance between the anastomosis and intersphincteric groove (DBAI) measured via 3D-EAUS.

Results: We retrospectively reviewed patients with a history of undergoing surgery for Hirschsprung disease who visited our outpatient clinic between December 2018 and December 2019. All patients underwent 3D-EAUS for DBAI measurement. We used the Krickenbeck classification to evaluate postoperative anorectal function.

Eleven patients (all males aged 3-14 years) were evaluated. Four (36.4\%), four (36.4\%), and three (27.3\%) patients had no soiling, grade 1 soiling, and grade 3 soiling, respectively. Four (36.4\%) and seven (63.6\%) patients had no constipation and grade 3 constipation, respectively. The median DBAl values were $7.0 \mathrm{~mm}, 8.4 \mathrm{~mm}$, and $5.6 \mathrm{~mm}(p=0.14)$ in the no soiling, grade 1, and grade 3 soiling groups, respectively.

Conclusions: 3D-EAUS enabled precise visualization of the anal anatomy and evaluation of the anastomosis. The DBAI was relatively short in patients with grade 3 soiling, although not significantly so. Further evaluation is warranted. Keywords: Hirschsprung disease, Endosonography, Fecal incontinence, Anal canal
\end{abstract}

\section{Background}

Patients with Hirschsprung disease undergo various surgeries [1]. Since laparoscopic pull-through surgery for Hirschsprung disease was first described by Georgeson in 1995 [2], and transanal endorectal pull-through by De La Torre-Mondragon in 1998 [3], transanal

\footnotetext{
*Correspondence: 884kentaro@gmail.com

${ }^{1}$ Department of Pediatric Surgery, Saitama Children's Medical Center, 1-2 Shintoshin, Chuo-ku, Saitama Prefecture, Saitama City 330-8777, Japan Full list of author information is available at the end of the article
}

rectal mucosectomy or transanal rectal dissection and anastomosis are the most common procedures for Hirschsprung disease.

A mucosectomy is usually performed $5-10 \mathrm{~mm}$ above the dentate line $[3,4]$. Some researchers have proposed another landmark such as the anorectal line [5], or 20 $\mathrm{mm}$ above the dentate line, to make an incision [6]. As such, the optimal distance from the incision or anastomosis to the anal verge is unclear. Moreover, we are unable to precisely measure how those distances changed after surgery. 
Recently, three-dimensional (3D) endoanal ultrasonography (3D-EAUS) has been used to assess fecal incontinence or other anal canal diseases in adult patients [7]. It allows precise anal evaluation; however, few studies have been performed involving children [8]. The 3D-EAUS enables us to visualize the anal structure precisely and allow us to differentiate the internal anal sphincter (IAS) and external anal sphincter (EAS): the IAS was shown as hypoechoic and the EAS as hyperechoic [9]. Then, we could measure the intersphincteric groove (the distal edge of the IAS) as a surrogate landmark of the anal verge.

Therefore, we aimed to describe our experience with 3D-EAUS in patients who underwent laparoscopicassisted pull-through surgery for Hirschsprung disease and to summarize the relationship between postoperative anal function and the distance between the anastomosis and intersphincteric groove (DBAI) measured via 3D-EAUS.

\section{Methods}

\section{Study design}

We retrospectively reviewed patients with a history of undergoing surgery for Hirschsprung disease, who visited our outpatient clinic between December 2018 and December 2019, and underwent 3D-EAUS. Patients who underwent surgery in other hospitals and those younger than 3 years old at the time of evaluation (owing to difficulty assessing anorectal function) were excluded from the study.

The study protocol complied with the Helsinki Declaration and was approved by the Research Ethics Committee of Saitama Children's Medical Center. The requirement for written informed consent was waived, and opt-out on the web was obtained instead because of the retrospective nature of the study.

\section{Surgical procedures}

We performed a laparoscopic-assisted pull-through surgery for Hirschsprung disease, and a transanal procedure was performed per the Soave-Denda procedure [10]. All operations were performed with at least one attending pediatric surgeon.

The patient was placed in the lithotomy position. We inserted the first trocar $(5 \mathrm{~mm})$ through the umbilicus using the open method. We subsequently added two additional trocars $(5 \mathrm{~mm})$ in the left and right abdomen to obtain a co-axial position. If necessary, we added one additional trocar $(4 \mathrm{~mm})$ in the suprapubic area.

During the laparoscopic procedure, we estimated the caliber change or transitional zone, followed by taking a full-thickness biopsy. We then dissected the colorectum sufficiently for the pull-through. When we reached the peritoneal reflection, we began the transanal procedure. A Lone Star Retractor System (CooperSurgical, Inc., Trumbull, CT) was used to expose the anal canal, and was hooked to the dentate line. We usually began the initial incision approximately 5-10 $\mathrm{mm}$ above the dentate line or around the anorectal line depending on the surgical team. We then started the mucosectomy until the peritoneal cavity. We added a myectomy of the posterior wall of muscular cuff to avoid anastomotic stricture according to Lynn's technique [11]. Afterwards, we confirmed the normal ganglionic colon by biopsy, and anastomosed the colon with the distal anus.

\section{Bowel management}

During the preoperative period, we used a glycerin enema to control constipation. In patients with relatively long aganglionic colons in whom constipation could not be controlled with only a glycerin enema, we inserted a long transanal drainage tube to irrigate the bowel instead of creating a stoma.

Postoperatively, we prescribed laxatives to manage constipation, and we prescribed loperamide to manage fecal incontinence. In the infant or toddler patients, we often prescribed a glycerin enema to control either constipation or fecal incontinence.

\section{Data collection}

We collected data on clinical characteristics including age, sex, birth weight, gestational age, comorbidities, operative management, and postoperative complications. We used the Krickenbeck classification to evaluate postoperative anorectal function [12]. We did not perform a manometry during the postoperative follow-up. We used 3D-EAUS (type 8838, BK Medical, Herlev, Denmark) to measure the DBAI (Fig. 1). The patient was placed in the supine position, then leg up or legs flexed position (similar to a lithotomy position), and the probe was introduced into the anal canal. The endoprobe was covered by a hard cone (outer diameter, $16.4 \mathrm{~mm}$ ) with a built-in linear array that rotated $360^{\circ}$ inside the transducer at a frequency range of 6-12 MHz, allowing a computer-controlled, automatic acquisition of the images in approximately $30 \mathrm{~s}$ without any external movement of the probe. The series of closely spaced two-dimensional images were combined to create a $3 \mathrm{D}$ volume shown as a cube. Because the IAS was shown as hypoechoic and the EAS as hyperechoic through the 3D-EAUS [9], we can find the intersphincteric groove clearly. Therefore, we could measure the DBAI (Fig. 1). The examination was performed without sedation (except in instances where the patient was undergoing other examinations 

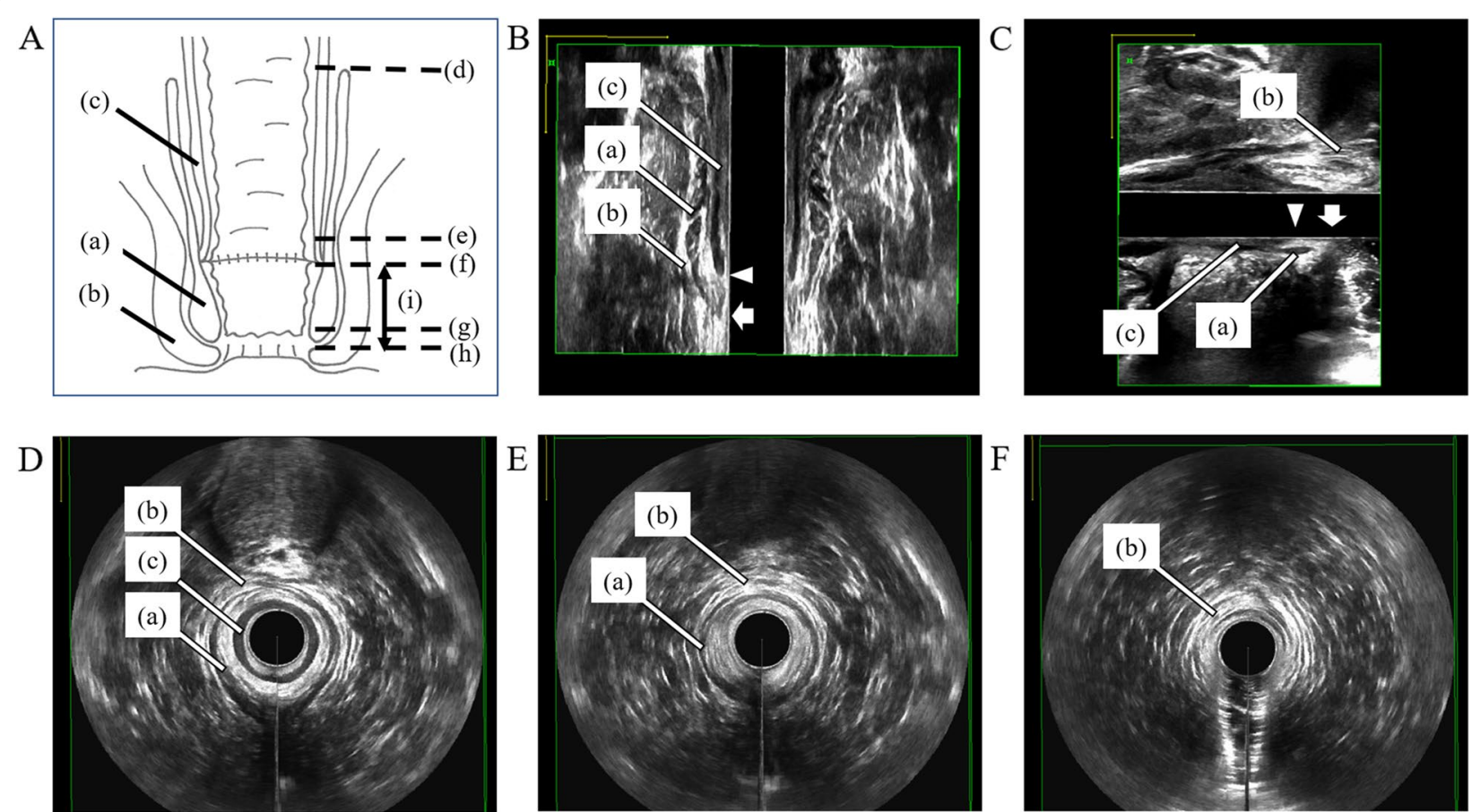

Fig. 1 A Schema of the coronal view. a Internal anal sphincter muscle (IAS). b External anal sphincter muscle (EAS). c Smooth muscle of the pull-through bowel. (d) The edge of the residual rectal muscular cuff. e Anorectal line. $\mathbf{f}$ The anastomosis. $\mathbf{g}$ The dentate line. $\mathbf{h}$ The intersphincteric groove. i Distance between the anastomosis and intersphincteric groove (DBAI). B Coronal view of 3D-EAUS (a) IAS and (c) smooth muscles are low echoic, and (b) EAS is high echoic. The distal edge of the (c) smooth muscle is the anastomosis (arrowhead) and the boundary between (a) IAS and (b) EAS is the intersphincteric groove (arrow). C Sagittal view of 3D-EAUS. The distal edge of the (c) smooth muscle is the anastomosis (arrowhead) and the boundary between (a) IAS and (b) EAS is the intersphincteric groove (arrow). D Axial view of 3D-EAUS between (d) and (f). Double low echoic circle are shown as a target sign because both (a) IAS and (c) smooth muscle are low echoic and (b) EAS is high echoic. E Axial view of 3D-EAUS between $(\mathbf{f})$ and $(\mathbf{h})$. Because there is no smooth muscle of the pull-through bowel, low echoic circle, (a) IAS, is single. F Axial view of 3D-EAUS below (h). Because there is no IAS, only high echoic circle, (b) EAS, is shown

requiring sedation, such as magnetic resonance imaging or computed tomography). The acquired images were read by a pediatric surgeon $(\mathrm{KH})$ and confirmed by a proctologist (TT).

\section{Statistical methods}

The primary endpoint was the relationship between the DBAI and anal function according to Krickenbeck classification, regarding constipation and fecal incontinence (soiling).

Categorical variables were presented as percentages (\%) and continuous variables presented as medians (range). Univariate analyses were performed using a non-parametric analysis (Mann-Whitney $U$ test) for continuous variables and Fisher's exact test for categorical variables. Statistical analyses were performed using EZR software (Saitama Medical Center, Jichi Medical University, Saitama, Japan), which is a graphical user interface for $\mathrm{R}$ version 3.3.1 (The R Foundation for Statistical Computing, Vienna, Austria) [13].

\section{Results}

Eighteen patients underwent 3D-EAUS during the study period. Seven patients were excluded from the study: two patients underwent an operation in another hospi$\mathrm{tal}$, and five patients were below 3 years of age at the time of examination. All patients' data are listed in Table 1. All patients were males; the median age at the time of evaluation was 7 (3-14) years. Incision information for the operation was quoted from the operation record. In particular, incisions in patients $1,4-8$, and 11 were commenced above the dentate line; however, the detailed distances were not described. Four (36.4\%), four (36.4\%), and three $(27.3 \%)$ patients had no soiling, grade 1 soiling, and grade 3 soiling, respectively. Four (36.4\%) and seven (63.6\%) patients had no constipation and grade 3 constipation, respectively.

The patients' characteristics and anal function are summarized in Table 2. The median ages at the time of evaluation were 8,6 , and 6 years old in the no soiling, grade 1 , and grade 3 soiling groups, respectively. The median ages were 8 and 6 years old in the no constipation and grade 


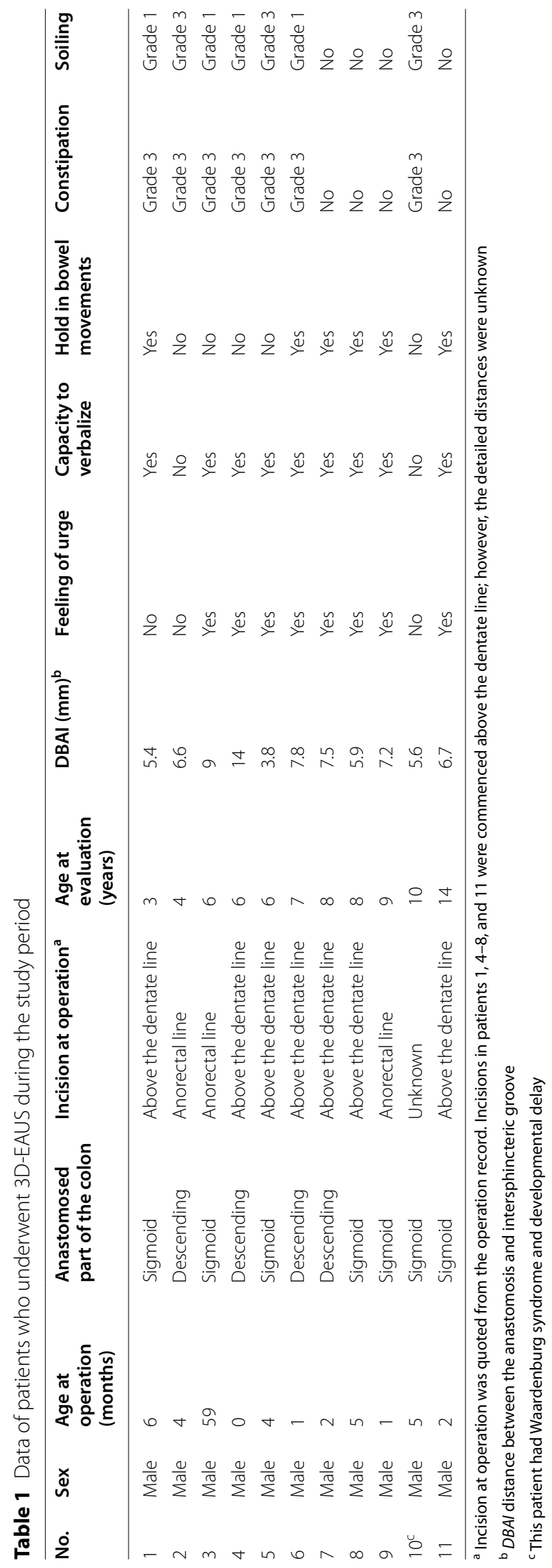


Table 2 Patient characteristics and anal function results

\begin{tabular}{|c|c|c|c|c|c|}
\hline & \multicolumn{3}{|l|}{ Soiling } & \multicolumn{2}{|l|}{ Constipation } \\
\hline & No soiling & Grade 1 & Grade 3 & No constipation & Grade 3 \\
\hline & $n=4$ & $n=4$ & $n=3$ & $n=4$ & $n=7$ \\
\hline $\begin{array}{l}\text { Age at evaluation } \\
\text { (years) }\end{array}$ & $8[8-14]$ & $6[3-7]$ & $6[4-10]$ & $8[8-14]$ & $6[3-10]$ \\
\hline Male (\%) & $4(100)$ & $4(100)$ & $3(100)$ & $4(100)$ & $7(100)$ \\
\hline Gestational age & $\begin{array}{l}36 w 6 d[33 w 2 d- \\
40 w 0 d]\end{array}$ & $\begin{array}{l}39 w 1 d[38 w 6 d- \\
40 w 0 d]\end{array}$ & $\begin{array}{l}40 w 3 d[38 w 4 d- \\
41 w 0 d]\end{array}$ & $\begin{array}{l}36 w 6 d[33 w 2 d- \\
40 w 0 d]\end{array}$ & $39 w 3 d[38 w 4 d-41 w 0 d]$ \\
\hline Birth weight (g) & 2743 [1763-3310] & 3036 [2756-3236] & 3152 [3140-3336] & 2743 [1763-3310] & 3152 [2756-3336] \\
\hline \multicolumn{6}{|l|}{ Comorbidity (\%) } \\
\hline None & $4(100)$ & $3(75.0)$ & $1(33.3)$ & $4(100)$ & $4(57.1)$ \\
\hline Jejunoileal atresia & $0(0.0)$ & $0(0.0)$ & $1(33.3)$ & $0(0.0)$ & $1(14.3)$ \\
\hline Intestinal malrotation & $0(0.0)$ & $1(25.0)$ & $0(0.0)$ & $0(0.0)$ & $1(14.3)$ \\
\hline $\begin{array}{l}\text { Waardenburg syn- } \\
\text { drome and develop- } \\
\text { mental delay }\end{array}$ & $0(0.0)$ & $0(0.0)$ & $1(33.3)$ & $0(0.0)$ & $1(14.3)$ \\
\hline $\begin{array}{l}\text { Age at operation } \\
\text { (months) }\end{array}$ & $2[1-5]$ & $3[0-59]$ & $4[4-5]$ & $2[1-5]$ & $4[0-59]$ \\
\hline Colostomy (\%) & $0(0.0)$ & $0(0.0)$ & $0(0.0)$ & $0(0.0)$ & $0(0.0)$ \\
\hline \multicolumn{6}{|c|}{ The part of the colon anastomosed with the anus (\%) } \\
\hline Sigmoid & $3(75.0)$ & $2(50.0)$ & $2(66.7)$ & $3(75.0)$ & $4(57.1)$ \\
\hline Descending & $1(25.0)$ & $2(50.0)$ & $1(33.3)$ & $1(25.0)$ & $3(42.9)$ \\
\hline \multicolumn{6}{|c|}{ Bowel management at examination } \\
\hline None (\%) & $4(100)$ & $0(0.0)$ & $0(0.0)$ & $4(100)$ & $0(0.0)$ \\
\hline $\begin{array}{l}\text { Osmotic laxatives } \\
(\%)^{\mathrm{a}}\end{array}$ & $0(0.0)$ & $0(0.0)$ & $0(0.0)$ & $0(0.0)$ & $0(0.0)$ \\
\hline $\begin{array}{l}\text { Stimulant laxatives } \\
(\%)^{\mathrm{b}}\end{array}$ & $0(0.0)$ & $1(25.0)$ & $0(0.0)$ & $0(0.0)$ & $1(14.3)$ \\
\hline Probiotics & $0(0.0)$ & $2(50.0)$ & $1(33.3)$ & $0(0.0)$ & $3(42.9)$ \\
\hline Glycerin enema (\%) & $0(0.0)$ & $4(100)$ & $3(100)$ & $0(0.0)$ & $7(100)$ \\
\hline $\begin{array}{l}\text { Other stool } \\
\text { softeners }{ }^{c}\end{array}$ & $0(0.0)$ & $1(25.0)$ & $0(0.0)$ & $0(0.0)$ & $1(14.3)$ \\
\hline $\begin{array}{l}\text { Transanal irrigation } \\
\text { (\%) }\end{array}$ & $0(0.0)$ & $0(0.0)$ & $0(0.0)$ & $0(0.0)$ & $0(0.0)$ \\
\hline Loperamide & $0(0.0)$ & $1(25.0)$ & $1(33.3)$ & $0(0.0)$ & $2(28.6)$ \\
\hline \multicolumn{6}{|c|}{ Postoperative complications } \\
\hline $\begin{array}{l}\text { Wound dehiscence } \\
\text { (\%) }\end{array}$ & $0(0.0)$ & $0(0.0)$ & $1(33.3)$ & $0(0.0)$ & $1(14.3)$ \\
\hline $\begin{array}{l}\text { Anastomotic stric- } \\
\text { ture (\%) }\end{array}$ & $0(0.0)$ & $1(25.0)+$ & $0(0.0)$ & $0(0.0)$ & $1(14.3)^{d}$ \\
\hline
\end{tabular}

Values are presented as median [range] or number (\%)

$A P$ anterior-posterior position

a Magnesium oxide

${ }^{\mathrm{b}}$ Sodium picosulfate and sennosides

Malt extract

${ }^{\mathrm{C}}$ This patient required strictureplasty later

3 constipation groups, respectively. One patient had Waardenburg syndrome and developmental delay.

The sigmoid/descending colon ratios (which is the part of colon anastomosed with the anus) were $3 / 1,2 / 2$, and $2 / 1$ in the no soiling, grade 1 soiling, and grade 3 soiling groups, respectively. The ratios were $3 / 1$ and $4 / 3$ in the no constipation and grade 3 constipation groups, respectively.

Four and three patients in the grade 1 soiling and grade 3 soiling groups, respectively, required a glycerin enema. 
Zero and seven patients in the no constipation and grade 3 constipation groups, respectively, received a glycerin enema. However, the reason to initiate a glycerin enema in all seven patients was to manage soiling at first, and the glycerin enema was still used at the time of examination.

One patient in both the grade 3 soiling and grade 3 constipation groups suffered from wound dehiscence, which was treated conservatively. Anastomotic stricture occurred in one grade 1 soiling and one grade 3 constipation patient, who required surgical strictureplasty later. Regarding anal function, all four patients with no soiling had no constipation. On the other hand, all patients with either grade 1 or grade 3 soiling had grade 3 constipation.

The primary endpoints are summarized in Table 3 . The median DBAI values were $7.0 \mathrm{~mm}, 8.4 \mathrm{~mm}$, and $5.6 \mathrm{~mm}$ in the no soiling, grade 1 , and 3 soiling groups, respectively. The DBAI values were $7.0 \mathrm{~mm}$ and $6.6 \mathrm{~mm}$ in the no constipation and grade 3 constipation groups, respectively, which were not significantly different. The DBAI of the patients with no soiling and grade 1 soiling was relatively longer than that of the patients with grade 3 soiling (Fig. 2).

\section{Discussion}

\section{Summary and interpretation of the results}

In the present study, we evaluated the postoperative anal anatomy in patients with Hirschsprung disease precisely via 3D-EAUS, especially the DBAI. We could clearly visualize the structures. In addition, we retrospectively reviewed the postoperative data regarding the relationship of anal function and the DBAI. Regarding the primary endpoint, the DBAI was shorter in patients with grade 3 soiling than in patients with no soiling or grade 1 soiling.

\section{Three-dimensional transanal ultrasound}

Although 3D-EAUS cannot visualize the dentate line that many surgeons use as landmarks, it can clearly show the IAS and EAS, and the boundary between the IAS and EAS, and the intersphincteric groove. There are some reports investigating transanal ultrasound in children with Hirschsprung disease [14]. However, all of them were twodimensional and only assessed the injury of the IAS and the EAS, not distance. We utilized 3D-EAUS, which enabled us to measure the sagittal and coronal distances with precision.

We performed this examination without sedation, which is useful for an imaging study in children. Moreover, because the image could be analyzed retrospectively, we were able to shorten the examination time [7]. Thus, 3D-EAUS is an effective instrument for the assessment of anorectal disease in children.

\section{Relationship between fecal incontinence and DBAI}

Since the inception of laparoscopic-assisted, pure transanal endorectal pull-thorough surgeries, various initial incisions have been described. De la Torre et al. started the mucosectomy with an incision $10 \mathrm{~mm}$ above the dentate line [3], and Langer et al. started $5 \mathrm{~mm}$ above the dentate line [4]. Although the procedure is not a mucosectomy, Pena et al. advocated an incision $20 \mathrm{~mm}$ above the dentate line to avoid sensory damage to the anal canal [6]. Few studies have tried to evaluate this optimal distance. Yamataka et al. [5] and Miyano et al. [15] showed that commencing the incision at the anorectal line (which is $12-15 \mathrm{~mm}$ above the dentate line) produced better postoperative bowel function in comparison to starting at the dentate line. Obata et al. [16] showed that patients with less than $5 \mathrm{~mm}$ between the incision and the dentate line have significantly more rectal mucosal prolapses within the month after the operation. This study did not, however, describe how the length was measured or any long-term bowel function.

In our study, the DBAI was measured objectively via 3D-EAUS and summarized with mid- to long-term outcomes. Our results showed that patients with grade 3 soiling had relatively short DBAI. Although we could not know details about injury of anal canal that is one of the main causes of fecal incontinence [17, 18], our results showed that a short distance may be related to fecal incontinence may be compatible with these previous studies. To measure how these distances changed after surgery, it would be better to measure the distance

Table 3 Primary endpoints

\begin{tabular}{|c|c|c|c|c|c|}
\hline & \multicolumn{3}{|l|}{ Soiling } & \multicolumn{2}{|l|}{ Constipation } \\
\hline & No soiling & Grade 1 & Grade 3 & No constipation & Grade 3 \\
\hline & $n=4$ & $n=4$ & $n=3$ & $n=4$ & $n=7$ \\
\hline \multicolumn{6}{|c|}{ Primary endpoints } \\
\hline $\operatorname{DBAI}(\mathrm{mm})^{\mathrm{a}}$ & 7.0 [5.9-7.5] & $8.4[5.4-14.0]$ & $5.6[3.8-6.6]$ & 7.0 [5.9-7.5] & $6.6[3.8-14.0]$ \\
\hline
\end{tabular}

Values are presented as median [range] or number (\%)

a $D B A /$ distance between the anastomosis and intersphincteric groove 
A

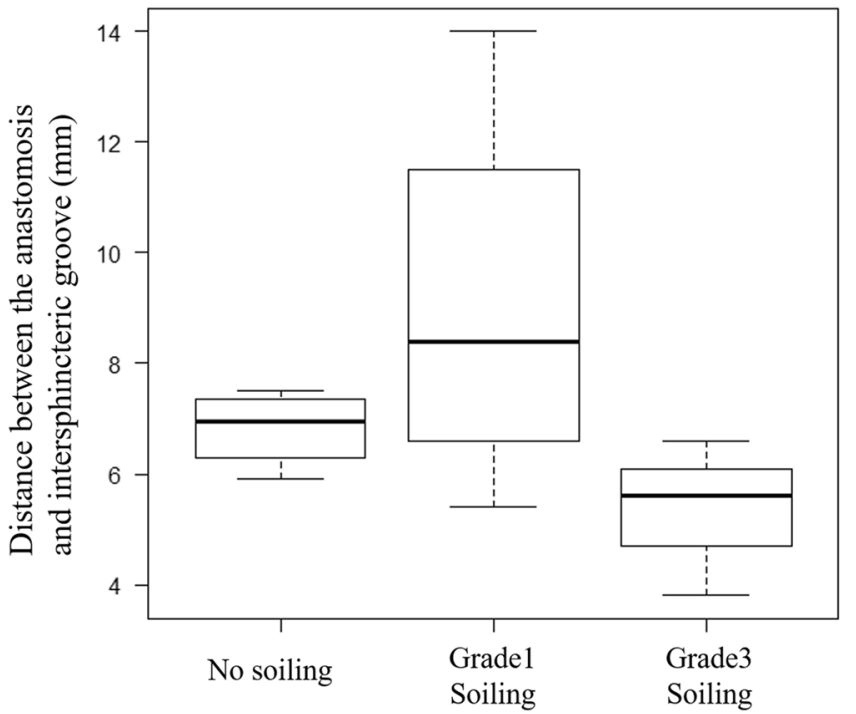

B

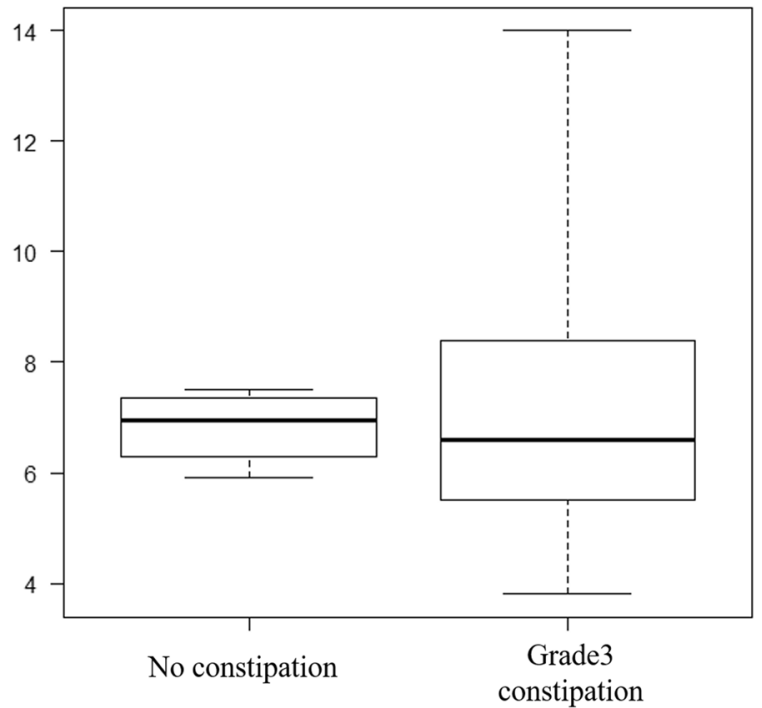

Fig. 2 The relationship between the distance from intersphincteric groove to the anastomosis and anal function. A Soiling and $\mathbf{B}$ constipation. The distance between the anastomosis and the intersphincteric groove is shorter in patients with grade 3 soiling than in the other groups. No relationship was found regarding constipation

by 3D-EAUS during surgery, but the diameter of the 3D-EAUS is not small enough to be used during surgery without any concern about the anastomosis. It would be best to wait until the 3D-EAUS becomes thin enough to be used during surgery.

As the patients aged after the operation for Hirschsprung disease, anal function is said to be improved significantly, with which our results are consistent. Various symptoms are usually said to resolve after 5 years of age [19]. We suspect that age may become a contributing factor because the anal canal increases in length as the patient gets older. However, the mean lengths of the anal canal at rest in adults are $16 \mathrm{~mm}(6-26$ $\mathrm{mm})$ in women and $22 \mathrm{~mm}(10-38 \mathrm{~mm})$ in men [20]. On the other hand, the anal canal lengths are $16.7 \pm 3.4 \mathrm{~mm}$ in neonates, $18.6 \pm 6.0 \mathrm{~mm}$ in infants, and $30.3 \pm 5.2 \mathrm{~mm}$ in children [21]. Therefore, the age of our participants may not have influenced the outcomes depending on the length of the anal canal. Further follow-up is warranted to investigate whether our young patients with grades 1 and 3 soiling will attain improved anal function.

Patients with a longer DBAI were thought to be concerned about constipation. However, unfortunately, we could not evaluate well regarding constipation because we could not eliminate the impact of bowel management medication. In seven patients judged as having grade 3 constipation prescribed a glycerin enema, the enema was usually used to manage fecal incontinence at first and is often continued until the patients grow up in our institute. We know anal function tests should be performed without any bowel management medication, but this was beyond our control owing to the retrospective nature of the study. Further investigation may be needed.

Moreover, since this was a retrospective descriptive study, we could not clearly conclude the optimal site of the incision. However, we believe that this study could suggest a novel evaluation technique for measuring the distance using 3D-EAUS and provide a rationale for further studies.

\section{Limitations}

This study had several limitations. Firstly, the Krickenbeck classification used to assess anal function should be performed without any bowel management medication. Unfortunately, contributing factors such as age and bowel management medication were affected owing to the retrospective nature of the study. In addition, we applied Krickenbeck classification, which is originally proposed to anorectal malformation patients in our Hirschsprung patients [12]. Second, this was a small sample size retrospective study in a single center. Since our patients received almost identical treatments, the distribution of DBAI was limited. Therefore, a larger sample size would better define the clinical differences. In addition, this study might be better performed as a prospective study with standardization of all confounding factors in terms of age, duration following surgery, or bowel management; however, since few previous studies have used endoanal 
ultrasound in pediatric patients, this remains a challenge. Therefore, we summarized our experience of endoanal ultrasound in patients after Hirschsprung disease surgery, and this study did provide some rationales for future studies. Third, the use of EAUS may stretch and alter the distance. We believe that the change is small, but we cannot measure the degree of change. Fourth, because only one pediatric surgeon $(\mathrm{KH})$ who has experienced 3D-EAUS in adult surgery can read the 3D-EAUS because this endoanal ultrasound is popular among adult proctologists but not among pediatric surgeons, we could not measure interrater agreement. Instead, to make the best effort to have the interpretation reliable, the interpretation was confirmed by an adult proctologist (TT) who could read the 3D-EAUS but was not used to see patients with Hirschsprung disease.

\section{Conclusions}

3D-EAUS enabled visualization of the precise anal anatomy and evaluation of the anastomosis. Because 3D-EAUS requires no sedation, it is quite useful for children. The DBAI measured via 3D-EAUS was relatively shorter in patients with grade 3 soiling than in patients with no soiling or grade 1 soiling. Further evaluation is warranted.

\section{Abbreviations \\ 3D-EAUS: Three-dimensional endoanal ultrasonography; DBAI: Distance between the anastomosis and intersphincteric groove; 3D: 3-dimensional; IAS: Internal anal sphincter; EAS: External anal sphincter. \\ Acknowledgements \\ The authors thank the other pediatric surgeons who have supported this study. We would like to thank Kawano Masanori Memorial Public Interest Incorporated Foundation for Promotion of Pediatrics for their support of this study. We would also like to thank Editage[http://www.editage.com]for providing English language editing.}

\begin{abstract}
Authors' contributions
Kentaro Hayashi, Tetsuya Ishimaru, and Tomoko Takahashi made substantial contributions to the conception, design of the work, the acquisition, analysis, and interpretation of data for the work. Kentaro Hayashi drafted the work and revised it critically for important intellectual content. Tetsuya Ishimaru, Tomoko Takahashi, Kanako Omata, Youhei Sanmoto, Yuta Hirata, Hiroshi Kawashima, and Tadashi Iwanaka revised the paper critically for important intellectual content. Kanako Omata, Youhei Sanmoto, Yuta Hirata, Hiroshi Kawashima, and Tadashi Iwanaka made substantial contributions to the acquisition of data for the work. All authors agreed to be accountable for all integrity of any part of the work are appropriately investigated and resolved. All authors read and approved the final manuscript.
\end{abstract}

\section{Funding}

This research received a grant from Kawano Masanori Memorial Public Interest Incorporated Foundation for Promotion of Pediatrics, who were not involved in the study design, data collection, analysis or interpretation, writing of this report, or the decision to submit this article.

\section{Availability of data and materials}

The datasets used and/or analyzed during the current study are available from the corresponding author on reasonable request. But the raw data of EAUS are not publicly available due to them containing information that could compromise research participant privacy.

\section{Declarations}

\section{Ethics approval and consent to participate}

The study protocol complied with the Helsinki Declaration and was approved by the Research Ethics Committee of Saitama Children's Medical Center (no. 2019-02-019). The requirement for written informed consent was waived because of the retrospective nature of the study.

\section{Consent for publication}

Informed consent was obtained in the form of opt-out on the website.

\section{Competing interests}

The authors declare that they have no competing interests.

\section{Author details}

${ }^{1}$ Department of Pediatric Surgery, Saitama Children's Medical Center, 1-2 Shintoshin, Chuo-ku, Saitama Prefecture, Saitama City 330-8777, Japan. ${ }^{2}$ Department of Gastroenterological Surgery, Kameda Medical Center, 929 Higashicho, Chiba Prefecture, Kamogawa City 296-8602, Japan. ${ }^{3}$ Bureau of Saitama Prefectural Hospitals, 3-15-1 Takasago, Urawaku, Saitama Prefecture, Saitama City 330-9301, Japan.

Received: 7 September 2021 Accepted: 13 November 2021

Published online: 10 February 2022

\section{References}

1. Kuroda T. Soave-Denda-Boley procedure. In: Taguchi T, Matsufuji H, leiri S, editors. Hirschsprung's Disease and the Allied Disorders. Singapore: Springer Nature Singapore Pte Ltd; 2019. p. 137-41.

2. Georgeson KE, Fuenfer MM, Hardin WD. Primary laparoscopic pullthrough for Hirschsprung's disease in infants and children. J Pediatr Surg. 1995;30(7):1017-21; discussion 21-22. https://doi.org/10.1016/00223468(95)90333-x.

3. De la Torre-Mondragon L, Ortega-Salgado JA. Transanal endorectal pullthrough for Hirschsprung's disease. J Pediatr Surg. 1998;33(8):1283-6. https://doi.org/10.1016/s0022-3468(98)90169-5.

4. Langer JC, Minkes RK, Mazziotti MV, Skinner MA, Winthrop AL. Transanal one-stage Soave procedure for infants with Hirschsprung's disease. J Pediatr Surg. 1999;34(1):148-51; discussion 52. https://doi.org/10.1016/ s0022-3468(99)90246-4

5. Yamataka A, Kaneyama K, Fujiwara N, Hayashi Y, Lane GJ, Kawashima K, et al. Rectal mucosal dissection during transanal pull-through for Hirschsprung disease: the anorectal or the dentate line? J Pediatr Surg. 2009;44(1):266-9; discussion 70. https://doi.org/10.1016/j.jpedsurg.2008.10.054.

6. Peña A, Bischoff A. Surgical treatment of colorectal problems in children. Switzerland: Springer International Publishing; 2015.

7. Santoro GA, Fortling B. The advantages of volume rendering in threedimensional endosonography of the anorectum. Dis Colon Rectum. 2007;50(3):359-68. https://doi.org/10.1007/s10350-006-0767-z.

8. Caldaro T, Romeo E, De Angelis P, Gambitta RA, Rea F, Torroni F, et al. Three-dimensional endoanal ultrasound and anorectal manometry in children with anorectal malformations: new discoveries. J Pediatr Surg. 2012;47(5):956-63. https://doi.org/10.1016/j.jpedsurg.2012.01.051.

9. Santoro GA, Di Falco G. Endoanal and endorectal ultrasonography: methodology and normal pelvic floor anatomy. In: Santoro G, Wieczorek AP, Bartram Cl, editors. Pelvic Floor Disorders. Italy: Springer-Verlag Mailand; 2010. p. 91-102.

10. Denda T, Katsumata K. New techniques for Hirschsprung's disease in infancy. J Jap Ass Pediatr Surg. 1966;2:37.

11. Lynn HB, van Heerden JA. Rectal myectomy in Hirschsprung disease: a decade of experience. Arch Surg. 1975;1 10(8):991-4. https://doi.org/10. 1001/archsurg.1975.01360140135026.

12. Holschneider A, Hutson J, Pena A, Beket E, Chatterjee S, Coran A, et al. Preliminary report on the International Conference for the Development of Standards for the Treatment of Anorectal Malformations. J Pediatr Surg. 2005;40(10):1521-6. https://doi.org/10.1016/j.jpedsurg.2005.08.002.

13. Kanda Y. Investigation of the freely available easy-to-use software 'EZR' for medical statistics. Bone Marrow Transplant. 2013;48(3):452-8. https://doi. org/10.1038/bmt.2012.244. 
14. Stensrud KJ, Emblem R, Bjørnland K. Anal endosonography and bowel function in patients undergoing different types of endorectal pull-through procedures for Hirschsprung disease. J Pediatr Surg. 2015;50(8):1341-6. https://doi.org/10.1016/j.jpedsurg.2014.12.024

15. Miyano G, Koga H, Okawada M, Doi T, Sueyoshi R, Nakamura H, et al. Rectal mucosal dissection commencing directly on the anorectal line versus commencing above the dentate line in laparoscopy-assisted transanal pull-through for Hirschsprung's disease: prospective medium-term follow-up. J Pediatr Surg. 2015;50(12):2041-3. https://doi.org/10.1016/j. jpedsurg.2015.08.022.

16. Obata S, leiri S, Akiyama T, Urushihara N, Kawahara H, Kubota M, et al. The outcomes of transanal endorectal pull-through for Hirschsprung's disease according to the mucosectomy-commencing points: a study based on the results of a nationwide survey in Japan. J Pediatr Surg. 2019;54(12):2546-9. https://doi.org/10.1016/j.jpedsurg.2019.08.035.

17. Bischoff A, Frischer J, Knod JL, Dickie B, Levitt MA, Holder M, et al. Damaged anal canal as a cause of fecal incontinence after surgical repair for Hirschsprung disease - a preventable and under-reported complication. J Pediatr Surg. 2017;52(4):549-53. https://doi.org/10.1016/j.jpedsurg.2016. 08.027.

18. De la Torre L, Cogley K, Santos K, Morales O, Calisto J. The anal canal is the fine line between "fecal incontinence and colitis" after a pull-through for Hirschsprung disease. J Pediatr Surg. 2017;52(12):2011-7. https://doi.org/ 10.1016/j.jpedsurg.2017.08.040.

19. Langer JC. Hirschsprung disease. In: Coran AG, Caldamone A, Adzick NS et al., editors. Pediatric Surgery. 7th ed. Netherlands: Elsevier Health Sciences; 2012. p. 1265-78.

20. Shorvon PJ, McHugh S, Diamant NE, Somers S, Stevenson GW. Defecography in normal volunteers: results and implications. Gut. 1989;30(12):1737-49. https://doi.org/10.1136/gut.30.12.1737.

21. Kumar S, Ramadan S, Gupta V, Helmy S, Atta I, Alkholy A. Manometric tests of anorectal function in 90 healthy children: a clinical study from Kuwait. J Pediatr Surg. 2009;44(9):1786-90. https://doi.org/10.1016/j.jpeds urg.2009.01.008

\section{Publisher's Note}

Springer Nature remains neutral with regard to jurisdictional claims in published maps and institutional affiliations.

\section{Submit your manuscript to a SpringerOpen ${ }^{\circ}$ journal and benefit from:}

- Convenient online submission

- Rigorous peer review

- Open access: articles freely available online

- High visibility within the field

- Retaining the copyright to your article

Submit your next manuscript at $\boldsymbol{\nabla}$ springeropen.com 